\title{
Study of the Characteristics of Chinese Guanxi and Its Influence on Business Development
}

\author{
Zhu Ding ${ }^{1,2, *}$ Haoqiang $\mathrm{Wei}^{3}$ \\ ${ }^{1}$ College of Management Engineering, Nanjing University, Nanjing, 210093, P. R. China; \\ ${ }^{2}$ Govtor Capital, Nanjing, 210093, P. R. China. \\ ${ }^{3}$ Shanghai National Accounting Institute, Shanghai, 201702, P. R. China; \\ *Corresponding author.Email: dingzhu163@126.com
}

\begin{abstract}
In Chinese society, Guanxi is an important part between people's interaction. In Chinese business, Guanxi also plays an important role and in many aspects, Guanxi has influenced the way how business in China operates. In order to understand the characteristics of Chinese guanxi and its influence on business development, this paper starts with the study about the emergence of Chinese Guanxi. Then the paper studies two important characteristics of Chinese Guanxi, which are respectively information share mechanism and trust in Chinese Guanxi. Also, the paper studies the main Guanxi in Chinese business, which are customer and supplier relationships and political relationships. The paper illustrates why these Guanxi are important in Chinese business and how these Guanxi will influence the business in China.
\end{abstract}

Keywords: Chinese Guanxi, information share mechanism and trust, customer and supplier relationships, political relationships

\section{INTRODUCTION}

The word "Guanxi" vividly sums up the unique way people interact with each other in Chinese society. In Chinese society, Guanxi is an important part between people's interaction [1]. In Chinese business, Guanxi also plays an important role and in many aspects, Guanxi has influenced the way how business in China operates.

Unlike western countries, China is a country which emphasize Guanxi in a large degree. The importance of Guanxi in Chinese culture derives from the historical reasons and is a unique phenomenon in the word [2]. Hence, Guanxi not only plays an important role in the way people interact with each other in China, but also influence the business in China. As a result, it is necessary to study the Characteristics of Chinese Guanxi and its influence on Chinese business.

This paper starts with the study about the emergence of Chinese Guanxi. Then the paper studies two important characteristics of Chinese Guanxi, which are respectively information share mechanism and trust in Chinese Guanxi. Also, the paper studies the main Guanxi in Chinese business, which are customer and supplier relationships and political relationships. The paper illustrates why these Guanxi are important in Chinese business and how these Guanxi will influence the business in China.

\section{CHARACTERISTICS OF CHINESE GUANXI}

\subsection{Emergence of Chinese Guanxi}

The word "Guanxi" vividly sums up the unique way people interact with each other in Chinese society. Some Chinese sociologists have pointed out that the emergence of Chinese Guanxi civilization is determined by the traditional economic foundation and the cultural form in China. In traditional Chinese civilization, agriculture industry is more important comparing to commerce. As a result, in earlier China, the country's economic base is concentrated on agriculture, forming a unique farming civilization. A farmer works from sunrise to sunset, and all his production activities are basically carried out in his land, hence the farmers' object of labor is his land and the wealth is determined by his land [3]. Consequently, farmers in earlier China can support himself by cultivating in their land, and they can even live a solitary and reclusive life. Farmers may have limited external needs and they do not need to interact with too many people. This reflects the realm of "small country and few people, even unable to interact with each other" in Laozi's theory [4].The land civilization has resulted in two results. Firstly, the farming civilization has made the farmers more secure and relies more on their hometowns. Many farmers have never left their hometowns in their whole lives. Secondly, agricultural civilization makes the relationship between each other extremely simple. The biggest use of farmers' social relations is to prevent the 
difficulties that individuals can not solve, such as natural disasters, or intergenerational replacement. Because of the age of the elderly, they are unable to farm, so they need young people to support them. Therefore, people live together through the clan, usually only interact with their blood related clan and neighbors. This makes kinship and geography an important part of the relationship.

The Confucian culture, represented by Confucius, provides a set of doctrines that can strengthen the order, harmony and stability of the social circle of acquaintances. Its logical starting point is that the family ethical relationship is the core, and then to expand outwards. The basic relationship begins with the husband and wife, and then extends to the father and son. With the number of children increases, brothers and sisters are also important. These form the family relationship. When children grow up, they begin to contact with the society and their relationship extends to teachers and students, friends and courtiers. In this circumstance, they handle the relationship between each other through the "ceremony" and "benevolence" way [5]. As a result, in Chinese society, there is a family-centered preface structure and a differential order pattern. In this pattern, social relations in China are gradually derived from individuals and with the increase of personal connections, personal connections form a social network. This is a network constructed from close to distant and from familiar to unfamiliar. As a result, in daily life and social exchanges, people always follow the logic from close to distant [6].

\subsection{Information Share Mechanism and Trust in Chinese Guanxi}

In the operation of people's relationships, information is usually not shared, but controlled. It is used to distinguish between related and unrelated parties to some extent. There is a high degree of trust in those who are in the same social network, but there is a general distrust of those who are not. As a result, the trust behavior of Chinese people is a special trust, which is constructed basing on blood community and basing on personal relationship and family or quasi-family relationship. The characteristic of special trust is that it only relies on others who have personal relationship with it, and does not trust outsiders [7].

Why is there such a state of trust between the inside and outside of the relationship circle? It has attracted the attention of many sociologists. Some people believe that this is related to the historical and cultural basis and tradition of Chinese country. In Chinese transition to the modern civilization, a mature market economy and society and the spirit of personality type and value is lack. Also, modern market economy society social spiritual resources are lack. In transition economies, legal protection and enforcement are relatively weak, and it is sometimes difficult to punish bad behaviors by legal means. As a result, reputation, as an informal system, often plays an important role. In earlier stages, Chinese society is an ethical society, a ritualistic society, a relational society, but not a totally legal society. Therefore, influenced by the familial ideology of Confucianism, interpersonal trust in Chinese society is constructed basing on reputation or relationship mechanism instead of depending on institutional constraints.

The "Guanxi" in Chinese society is constructed basing on Confucian culture and it is a pragmatic way of doing things that emphasizes reciprocity. In social communication, the main function of relationship is that it guarantees the trust needed in each stage of communication. Relationships imply mutual obligations, and a sense of obligation leads to trustworthy behavior. Rewarding obligations are at the heart of relationships. If a person fails to perform his obligations, he will lose face, he will not only be condemned by others, and probably will pay great cost and at last loss of network and its social resources contained in. As a result, relationship exists, to a certain extent depends on the external system environment. When people lack of institutional guarantee and punitive measures, they can only turn to the "relationship". This is because Guanxi does not require formal institutional guarantees, but relies on the reputation and self-discipline of both parties.

\section{CHINESE GUANXI IN BUSINESS}

\subsection{Main Guanxi in Business}

Obtaining competitive advantage and excellent performance is the core issue in the enterprise management strategy. In China, as an emerging economy, social relations are often an important strategic choice for enterprises to acquire resources and to cope with the uncertain environment due to the volatility in business environment. Social relationships which are operated through informal, person-to-person social mechanisms can help companies to overcome the limitations of a weak institutional infrastructure, especially in uncertain times [8]. In emerging economies, where market support is lacking, governments play an important role in regulating industrial development, guiding business policy and influencing companies' operations. For this reason, establishing relationships with different government agencies is crucial to the survival of enterprises. At the same time, building relationships with business partners is also important for business.

\subsection{Customer and Supplier Relationships}

Customers and suppliers are very important non-financial stakeholders of enterprises. They constitute the most important part of the supply chain, which is related to the operation of the entire business process and plays a decisive role in strategy formulation, operation and management process of a company. The relationship formed with the customer and the supplier is called the customer-supplier relationship, which includes the cooperative relationship and the competitive relationship. At present, the academia and the theoretical circle has found that the customersupplier relationships may have apparent influence on 
company behavior. And the value of the company may also be influenced by its customer-supplier relationships.

\subsubsection{Customer relationships}

Customers have a huge impact on the development of enterprises and it is mainly reflected in the following aspects: First, customers are the main provider of the revenue. Strategically, the customer can be regarded as the most important financial custodian of the company because the customers can strongly affect the financial balance of the enterprises, and the company's income level is mostly controlled by the customer's needs. Second, customers can be a resource for companies to learn and innovate. Because the customers have a point of view about which products or services they need, they can choose other products when a company can no longer meet the needs of them. As a result, customers are also a catalyst for the company to update its technology or products, helping the company to achieve a lasting competitive advantage. Hence, there is no doubt that customers are the source of corporate profits. How to manage customers effectively is the key to the success of an enterprise. In the modern environment of fierce competition, it is the key for any enterprise to win the competition to adapt to the needs of customers, give customers the right to choose their own products, and let customers get what they really want.

\subsubsection{Supplier relationships}

Supplier relationship is formed through the interaction between companies and their customers in the procurement activities. Companies handle the relationship with their suppliers to obtain basic resources, in order to expand market share, reduce product costs, and form competitive advantages. Since the $21 \mathrm{st}$ century, with the rapid development of economic globalization and modern information technology, the competition between enterprises is getting fiercer and fiercer. To remain competitiveness, companies must constantly improve their internal processes and improve the quality of their products. However, only relying on the enterprise themselves to achieve advantages is not enough, enterprises have to cooperate better with their suppliers. According to business types, suppliers can be divided into raw material suppliers, auxiliary material suppliers, service suppliers and equipment suppliers. In many enterprises, according to the classification of suppliers, enterprises have different evaluation standards and management requirements on these suppliers to achieve better cooperation with suppliers and form mutual benefit.

Enterprises can find their suppliers through the network, bidding, exhibition and other ways. In short-term cooperation, enterprises mainly consider whether the suppliers' quality can meet the requirements, whether the delivery is timely, whether the service is good and whether the price is competitive. From the perspective of long-term cooperation, enterprises should also consider the management base of suppliers when selecting suppliers to ensure the long-term cooperation is possible. Evaluating suppliers in supplier relationship management is very important, this is an effective way to maintain the long-term development of supplier relationship. The enterprises can confirm the supplier's qualification, check the performance of suppliers' contracts, calculate the on-time delivery rate of suppliers, and measure the research and development capability of suppliers. All in all, the goal is to form a winwin relationship between companies and its customers.

\subsection{Political Relationships}

In the process of China's economic transformation, enterprises are facing a rapidly changing external institutional environment, and the relationship between government and business is in a deep adjustment. Enterprises should not only promote innovative development according to their own conditions, but also consider the system environment. Hence, it means that enterprises not only need their own exploration and practice, but also need the government to understand the situation and support their business. The establishment of the new type of "pro-government" relationship between government and business provides new opportunities for enterprises to live in the market [9]. In order to effectively compete in the market and effectively utilize non-market factors such as the institutional environment, enterprises need to develop effective political relationships with the government.

To some extent, political relationships can help enterprises develop better and enable them to break through various regulations and entry barriers, obtain more preferential tax rate, patent protection and other conditions. As a result, it can help enterprises to obtain more space for survival and development. However, political relationship may also bring extra cost and inertia to enterprises, making them dependent on political relationship, which is not conducive to the long-term development of the enterprises [10]. As a result, enterprises have to handle the political relationship well.

\section{CONCLUSIONS}

In conclusion, Chinese Guanxi civilization is determined by the traditional economic foundation and the cultural form in China. In the operation of Chinese people's relationships, information is usually not shared, but controlled. It is used to distinguish between related and unrelated parties to some extent. In Chinese Guanxi, there is a special trust. The characteristic of this special trust is that it only relies on others who have personal relationship with it, and does not trust outsiders.

For Chinese business, obtaining competitive advantage and excellent performance is the core issue in the enterprise management strategy. In China, establishing relationships with different government agencies is crucial to the survival 
[10] C.L. Chang. The Effect of an Information Ethics Course on the Information Ethics Values of Students - a Chinese Guanxi Culture Perspective. Computers in Human Behavior, 27(5), p.2028-2038.

\section{REFERENCES}

[1] X.P. Chen, C.C. Chen. On the Intricacies of the Chinese Guanxi: a Process Model of Guanxi Development. Asia Pacific Journal of Management, 21(3), 305-324.

[2] J.F. Anne, S. Tsui, K. Xin, B.S. Cheng. The Influence of Relational Demography and Guanxi: the Chinese Case. Organization Science, 9(4), 471-488.

[3] S. Marquet, F.O. Sánchez, M. Arias, J. Rodríguez, S.C. París, E. Skamene. Guanxi and Chinese Middle Managers Knowledge Distribution. 89(9), 4351-4358.

[4] A.S. Tsui, J.L. Farh, Where Guanxi Matters: Relational Demography and Guanxi in the Chinese Context[J]. 1997, 24(1):56-79.

[5] J.D. Luo, \& Y.C. Yeh. Neither Collectivism nor Individualism: Trust in the Chinese Guanxi Circle. Journal of Trust Research, 2012, 2(1), 53-70.

[6] Y.J. Bian, \& L. Zhang. Corporate Social Capital in Chinese Guanxi Culture. Research in the Sociology of Organizations, 2014 40, 421-443.

[7] P.W. Hom, Z.X. Xiao. Embedding Social Networks: How Guanxi Ties Reinforce Chinese Employees' Retention. 116(2), 188-202.

[8] H.T. Yang \& Y. Jiang. Management of the Relation Between the Enterprise and Supplier Based on the Chinese GUANXI Culture. 4th International Conference on Wireless Communications, Networking and

[9] P. Helen, K. Kenneth, C. Zhang. An Empirical Evaluation of R\&D-Marketing NPD Integration in Chinese firms: the Guanxi Effect. Journal of Product Innovation Management, 2009, 26(6), 640-651. 